\title{
Understanding the Effect of Internet Addiction on Student Academic Engagement
}

\author{
Anjali Singh, National Institute of Industrial Engineering, Mumbai, India \\ Dinesh Kumar Srivastava, National Institute of Industrial Engineering, Mumbai, India
}

\begin{abstract}
The aim of the study is to understand the effect of internet addiction on student academic engagement. There are numerous studies explaining the negative relationship between internet addiction and academic performance; still, very few studies could explain how the excessive use of the internet disrupts students' academic engagement. This study focuses on two aspects, academic engagement (dedication and vigor) and internet addiction (emotional and cognitive preoccupation with internet and loss of control and interference with daily life). Data was collected from 152 students in an institute in India through questionnaires. The data was analyzed using correlation and regression. The analysis showed that internet addiction has a significant, negative impact on vigor and dedication. Interestingly, it was found that emotional and cognitive preoccupation with the internet is not a significant predictor of internet addiction and loss of control.
\end{abstract}

\section{KEYWORDS}

Academic Performance, Engagement, Internet Addiction, Problematic Internet Use, Smartphone Addiction

\section{INTRODUCTION}

The growth of the internet can be understood by the mere fact that more than 500 hours of video were uploaded to YouTube every minute. Which is almost 30,000 hours of newly uploaded content per hour (Statista, 2019). Similar growth can be seen in social media sites like Facebook and chats like WhatsApp. Moreover, with the new advancement in technologies, the internet, smartphone devices, iPad, tablets have become an integral part of everyone's life be it students, teachers, businessmen, government officials. India's internet penetration has reached 483 million (2018) an increase of 10.5\% from 2017 (Statista, 2020). As per the Statista, 2020 report, India has the second-highest number of internet users after China. The internet has been a part of our lives for a couple of decades; however, the biggest shift came around a few years back when mobile data became cheap enough to be affordable to the lower middle class and lower class of the population (Jeffery, 2013). internet with the emergence of social media sites, chat platforms, WhatsApp, YouTube led to the boom in the data world. Consequently, the number of people availing of these services rose, and with the arrival of free internet, the number of people using smartphones and mobile data increased to such an extent that now everyone has the data and mobile facility (Vaidya \& Pathak, 2016).

Although cheap and easy mobile internet comes with great benefits, the excessive usage of the same can have a dreadful effect on the lives of the people especially the youth of the country. The number of youth percentage using the internet and smartphone rose to $49 \%$ (WhatsApp revenue and 
usage statistics report, 2020). Considering the current demographic trend in India, the youth are leading in the usage of such technologies (Kumar \& Rajpal, 2018). Among these youths, some are students while some are working professionals. Moreover, there has been a myriad of studies on the benefits of the internet and new technologies but very few studies have explained the negative impact of the internet and other new technologies on their academic performance (Durak, 2019). With the benefits of internet penetration, there seems to be a rise in the threat from the excessive use of the internet, especially among the students. Excessive use of the internet and internet devices causes addiction which affects negatively. In India, there are at least $24.6 \%$ of adolescents have an internet addiction (Preksha \& Maheshwari, 2018; Sharma, 2016). In the past few years, internet use has increased many folds so much so that there is a rising threat of students getting addicted to the internet.

Some studies have stated the negative impact of the internet on student performance (Shambare, Rugimbana, \& Zhowa, 2012) but not many have delved into details as to what are the different ways in which the internet disrupts the academic performance of the students in India. According to Beard and Wolf (2011) - internet addiction can be defined as "Overuse of the internet leading to impairment of an individual's mental, emotional and psychological states as well as their scholastic, occupational and social interactions". The aim of the study is to understand the level of addiction in students as well as the impact of internet addiction aspects like "emotional and cognitive preoccupation of the internet" and "loss of control and interference with daily life" on students' academic engagement.

\section{LITERATURE REVIEW}

Addiction is usually related to drugs, alcohol, or any other substance use which causes the individual to excessively engage in the consumption of the above things leading to various health effects. Similarly, excess use of the internet also causes various problems in the lives of the people like reduced work performance (Robert Half International, 1996), The studies conducted so far refereed interned addiction as excessive unhealthy utilization of internet and allied devices. (Fu et al., 2010; Griffiths, 2000; Scherer, 1997; Young, 1998). Which causes one to lose its ability to control the time spent online on the internet (Beard, 2005). The mental or emotional disturbance in the psychological state of the individual caused due to excessive usage of the internet is defined as internet addiction (Beard $\&$ Wolf, 2001). Overuse of the internet in Facebook and WhatsApp also influence the social life of the individuals by not being socially active and neglecting social activities, continuously engaging in a virtual world without interacting with others creates disharmony within the society causing a lot of issues (Araby. Et.al, 2020).

Although internet addiction can be seen in any age group, it is more profoundly seen in students. Hence, they are more susceptible to developing this behavior as they are actively involved in online activities. (Lee, 2010; Nalwa \& Anand, 2003; Yang \& Tung, 2007). There have been many studies conducted worldwide to explore the internet addiction behavior in an individual especially the youth, the students e.g., Awan \& Khan (2017) studied internet addiction (IA) in college students in South Korea. They examined the IA level of students as compared to the earlier studies and found out $10 \%$ of them were highly addicted as compared to $3.1 \%$ in earlier studies. This rise has been associated with the rise of smartphones and the internet. Further, they also studied that internet addiction is not gender-specific. It applied equally to both males and females. After understanding the behavior there was a need to understand what factors or aspects give rise to this behavior. Arefin, et al. (2017) has studied the factors that affect the level of smartphone addiction along with its effects on the academic performance of private university students in Bangladesh. They have identified five factors namely positive anticipation, increased impatience and intolerance, withdrawal, daily life disturbance, and cyber friendship as significant factors that determine the addiction of smartphone use of business students and have an impact on their academic performance. Shammimul, et al. (2018) has studied the various factors that influence the learning performance of the students in Bangladesh. They examined 
the factor - academic self-efficacy as a mediator in improving the learning performance of students and especially as a mediator between general internet use and students' learning performance.

Chukwuere, et al. (2017) has studied that students in South Africa spent a lot of time buying, new devices like smartphones, installing apps, charging, and recharging them. This incurs a financial burden on them for maintaining such high-end devices. This further has many negative impacts on their academic performance. Yafi \& Masri (2017) has studied the relationship between social networking sites (SNS) usage and user's academic performance in Qatar. They divided them into three groups- a) passive users- low usage b) engaged users- normal usage c) addicted users - high usage. The results showed that engaged users reported higher academic performance as compared to their addicted or passive peers. Thus, contradicting the linear relationship between SNS usage and academic performance. Yeap et al. (2016) have studied the impact of internet addiction on three aspects of academic engagement- dedication, vigor, and absorption among students of Malaysia and found out that internet addiction has a negative impact on vigor but no impact on dedication and absorption. Similar other studies have also been conducted. However, very few studies have been conducted to explore this phenomenon in the Indian scenario.

This study will help in determining the internet addiction level as well as exploring the impact of internet addiction on students' academic engagement. internet addiction has been factored into two aspects viz, emotional, and cognitive preoccupation with the internet and loss of control and interference with daily life (Faraci, 2013). When exploring the effects of internet addiction on students' academic performance, students' academic engagement is a good predictor in terms of student's vigor, dedication, and absorption (Schaufeli \& Baker, 2004), However, for the sake of this study, only vigor and dedication is adopted. This leads to our research question as mentioned below:

RQ1: What is the internet addiction level of the students?

RQ2: Does the loss of control and interference in daily life has any impact on the vigor and dedication of business students?

RQ3: Does emotional and cognitive preoccupation with the internet has any impact on the vigor and dedication level of business students?

Hence, the objective of our study is, to understand the internet addiction level of the students and the effect of internet addiction in terms of loss of control and interference with daily life and emotional and cognitive preoccupation with the internet on academic engagement of students in terms of the vigor and dedication of students.

\section{Variables}

Independent Variables

1. Internet Addiction: Young describes internet addiction as behavior related to online activities that cause one to obsess about something like chat, messaging, etc. which hampers their dayto-day life by creating stress in social and personal life (Young, 1998). It has many names like internet addiction or internet dependency or internet compulsivity. It is nothing but a compulsive behavior that takeover the addict's life. It makes the individual feel that the internet is the most important thing in life and takes the priority over its own life or family, work, friends, or relatives. The addict's life revolves around the internet.

2. Emotional and cognitive preoccupation with the internet: It means over-relying on online life (Cernija, 2019). In many circumstances, it will make individual to prefer online conversation, or a motivation to choose an online tool like a chatbox, Facebook to make oneself comfortable. It is like you are still thinking about going online when you are offline (Andangsari et al., 2019). Emotional and cognitive preoccupations with the internet include words such as the presence of 
negative feelings (e.g., feeling bored, depressed, or nervous) and obsessive thoughts about the internet (Fioravanti \& Casale, 2015).

3. Loss of control and interference with daily life: Loss of control and interference with daily life is the inability to control the amount spent online (e.g., staying online longer than intended) which ultimately disrupts the daily functioning (e.g., sleep disturbances and low school/job performance or productivity) (Fioravanti \& Casale, 2015).

Dependent Variables

1. Academic engagement: The level of the performance of the students focused on their studies can be measured with engagement as they would invest highly in academic learning and are normally dedicated towards their studies, and they are often immersed in their study activities (Bakker et al., 2015). Schaufeli et al. (2002) explain engagement as a multifaceted aspect comprising Vigor, dedication, and absorption.

2. Vigor: In the student context, vigor refers to the ability of the student to invest a high level of effort displaying high energy, curiosity in studies (Schaufeli et al., 2002, p. 465).

3. Dedication: Dedication explains how enthusiastic the student is, how inspired the student is, towards the studies. (Schaufeli et al., 2002, p. 465).

\section{Hypotheses}

The more the student rely on the internet for every aspect of his life the more it affects the energy and enthusiasm towards the studies because the rising interest in internet life will consume the energy which needs to be utilized in academic or learning purpose and ultimately very less energy will be left for doing anything losing interest in academic activities which is nothing but vigor of the student which leads to hypothesis.

H1: Emotional and cognitive preoccupation with the internet has a negative impact on students' vigor.

Similarly, when the student relies more on the internet, the dedication towards the studies decreases as the student would spend most of the time on internet, the level of motivation for studying and carrying out other activities would decrease. The student will feel less inspired to indulge in studies. Which leads to our second hypothesis.

H2: Emotional and cognitive preoccupation with the internet has a negative impact on students' dedication.

The less control the student has over the daily activities of life the less attention student would be able to pay towards studies. The student might not be able to control the time he/she spent online chatting, playing games, or talking to somebody which ultimately results in reduced interest or energy on studies thus impacting the studies as well as the vigor of the student.

H3: Loss of control and interference with daily life has a negative impact on students' vigor.

Similarly, with less amount of control in life, the student would lose attention student and may not be able to focus on studies. The student might get overwhelmed with the stories and posts of the friends and colleagues thus criticizing themselves and thinking little of themselves resulting in reduced motivation and fell less inspired towards studies thus impacting the studies as well as the dedication level of the studies (Figure 1). 


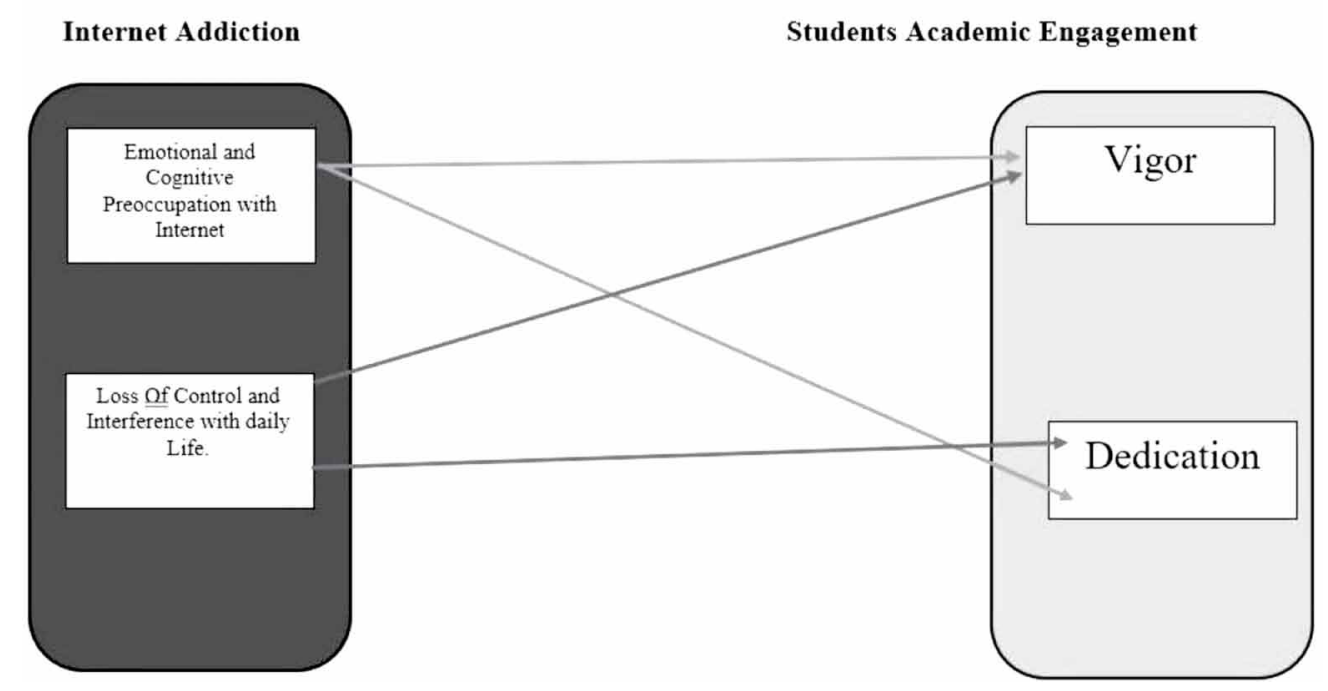

H4: Loss of Control and interference with daily life has a negative impact on students' dedication.

\section{RESEARCH METHOD}

An empirical study was conducted for understanding the effect of internet addiction on students' academic engagement. Data was collected from 152 students using a structured questionnaire with a 6-point rating scale. A convenience sampling method was used for data collection. The measurement scales for internet addiction have been derived from Young's (2008) IAT scale and Academic engagement from the UWES scale modified for students. The reliability and validity of the questionnaire have also been tested.

The academic engagement has been used as a dependent variable in this study in terms of their vigor and dedication towards studies. Further, SPSS 20 software was used to analyze the data. Finally, correlation and regression were used in SPSS to analyze the data.

Internet Addiction scale - The internet addiction Test (IAT) by Young (1998) originally consists of 20 items of which 17 items were selected which are rated on a 6-point-Likert scale from 1 ("does not apply") to 6 ("always"), Item 17 ("Do you try to cut down the amount of time you spend online and fail?") and item 8 ("Does your performance or productivity suffer because of the internet?") presented double loading and were eliminated (Faraci 2013). The items comprise several facets of Internet addiction, such as loss of control and interference with daily life (7 items), Emotional and cognitive preoccupation with the internet (11 items). The Cronbach alpha for the scale was 0.88 .

Academic Engagement measure- Using the Utrecht Work Engagement Scale for students (UWES17) developed by Schaufeli et al. (2003). With 6 items for vigor and 5 for dedication. 6 items of absorption were not considered here as the focus was only on dedication and vigor. The Cronbach alpha for the scale was 0.708 . The items with a 6 -point Likert scale $(1=$ never, $2=$ almost never, $3=$ rarely, $4=$ sometimes, $5=$ very often, and $6=$ =always) are used. 


\section{Sample}

A sample of 152 business management students from the national institute of India has been taken of which $23.4 \%$ were females (31) and $79.6 \%$ (121) were males. Among them, most of the students $50.65 \%$ are from the $20-25$ age group. While $46.71 \%$ were from the $25-30$ age group and very few students $1.31 \%$ and $1.31 \%$ are from $30-35$ and 35 and above age group. This shows that almost $97 \%$ of the students are from the $20-30$ age group indicating the younger population (Table 1).

\section{DATA ANALYSIS}

Initially, the addiction level is identified in the sample with the help of the IAT 20 test of Young 1998. Internet Addiction Test (IAT) is a reliable and valid measure of internet addiction by Dr. Kimberly Young comprising 20 items that measure mild, moderate, and severe levels of internet Addiction. The results show that $63 \%$ of the students are moderately addicted to the internet which encompasses 82 males and 14 females. While $30 \%$ are mildly addicted to the internet a minuscule $6 \%$ are severely addicted to the internet. Among males and females, $67 \%$ of males are moderately addicted to the internet and $25 \%$ of them are mildly addicted to the internet. The case with females is different $48 \%$ are mildly addicted while $45 \%$ are moderately addicted. This shows that the sample is moderately addicted to the internet and if proper actions are not taken, they might move to the severely addicted category (Table 2).

\section{Reliability Analysis}

The reliability analysis of the scale was conducted using SPSS 20 accordingly the $\alpha$ values are mentioned in Table 3 for variables included in the study. As the value of Cronbach alpha is greater than 0.60 , they are above the cutoff and hence could be considered reliable enough for progressing with the study.

\section{Means, Standard Deviations and Correlations}

Means, Standard Deviations and Correlations. It also mentions the Cronbach alpha value of the Variables. The control variables (age, gender, and education) are also included. The mean for emotional and cognitive preoccupation with the internet has a mean of 28.68, mean for loss of control and interference with daily life is 23.98 , mean for vigor is 23.98 while for dedication is 19.80 i.e., more

\begin{tabular}{lll}
\hline Demographic details & Numbers & Percentage \\
Gender Male & 121 & 79.6 \\
Female & 31 & 20.34 \\
Age $20-25$ & 77 & 50.65 \\
$25-30$ & 71 & 46.71 \\
$30-35$ & 2 & 1.31 \\
35 and above & 2 & 1.31 \\
\hline
\end{tabular}


Table 2. Addiction level of the sample

\begin{tabular}{lllllll}
\hline Points range & No of students & Percentage & Males & Male \% & Females & Female \% \\
$20-49$ (mild) & 46 & 30.26 & 31 & 25.62 & 15 & 48.39 \\
$50-79$ (moderate) & 96 & 63.16 & 82 & 67.77 & 14 & 45.16 \\
$80-100$ (severe) & 10 & 6.58 & 8 & 6.61 & 2 & 6.45 \\
Total & 152 & 100 & 121 & 100 & 31 & 100 \\
& & & & & & \\
\hline
\end{tabular}

Table 3. Reliability

\begin{tabular}{lll}
\hline \multicolumn{1}{c}{ Constructs } & Source & $\alpha$ \\
\hline Internet addiction & Young K S (1998) & 0.88 \\
$\begin{array}{l}\text { Emotional and cognitive preoccupation with } \\
\text { Internet }\end{array}$ & $\begin{array}{c}\text { Faracci.P, Craparo.G, Messina.R, Severino.S } \\
(2013)\end{array}$ & 0.85 \\
Loss of Control and interference with daily life. & $\begin{array}{l}\text { Faracci.P, Craparo.G, Messina.R, Severino.S } \\
(2013)\end{array}$ & 0.81 \\
Students' Academic engagement & Schaufeli.W, Bakker. A (2006) & 0.71 \\
Vigor & Schaufeli.W, Bakker.A (2006) & 0.68 \\
Dedication & Schaufeli.W, Bakker.A (2006) & 0.65 \\
\hline
\end{tabular}

clustered around the mean. In Table 4, there exists a correlation between vigor and ECPI, vigor and LOC, Dedication, and LOC while there exists a very low correlation between dedication and ECPI.

From Table 5, the independent variables like emotional and cognitive preoccupation with the internet and loss of control and interference with daily life significantly related to the dependent variable vigor and dedication as per F5,146 $=13.286, \mathrm{p}<0.05$. R-value is 0.559 and $\mathrm{r}$ square value as 0.313 indicating $31.3 \%$ of the variance in the vigor of the students can be predicted by internet addiction aspects - loss of control and interference with daily life and emotional and cognitive

Table 4. Means, Standard Deviations and Correlations

\begin{tabular}{|c|c|c|c|c|c|c|c|c|c|c|}
\hline & & 1 & 2 & 3 & 4 & 5 & 6 & 7 & M & $\mathrm{SD}$ \\
\hline 1 & ECPI & 1 & & & & & & & 28.68 & 8.15 \\
\hline 2 & LOC & $.62^{* *}$ & 1 & & & & & & 23.98 & 5.95 \\
\hline 3 & Vigor & $-.28^{* *}$ & $-.47^{* *}$ & 1 & & & & & 23.88 & 4.27 \\
\hline 4 & Dedication & $-.17^{*}$ & $-.38^{* *}$ & $.67^{* x}$ & 1 & & & & 19.80 & 4.94 \\
\hline 5 & Age & $.32^{* *}$ & .14 & .00 & .14 & 1 & & & 1.53 & .60 \\
\hline 6 & Gender & -.12 & -.07 & $-.21^{*}$ & -.16 & .04 & 1 & & 1.20 & .40 \\
\hline 7 & Education & .03 & -.01 & .15 & $.32^{* *}$ & $.20^{*}$ & .15 & 1 & 1.64 & .53 \\
\hline
\end{tabular}


Table 5. Multiple regression analysis

\begin{tabular}{|c|c|c|c|c|c|c|c|c|c|c|}
\hline \multirow{3}{*}{ Predictors } & \multicolumn{10}{|c|}{ Dependent Variable } \\
\hline & \multicolumn{4}{|c|}{ Vigor } & \multicolumn{6}{|c|}{ Dedication } \\
\hline & B & SE & Beta & $\mathrm{t}$ & sig. & B & SE & Beta & $\mathrm{t}$ & Sig. \\
\hline (Constant) & 33.222 & 1.810 & & 18.356 & .000 & 24.807 & 2.084 & & 11.902 & .000 \\
\hline ECPI & -.030 & .048 & -.057 & -.616 & .539 & -.004 & .056 & -.007 & -.080 & .936 \\
\hline LOC & -.329 & .063 & -.458 & -5.245 & .000 & -.339 & .072 & -.408 & -4.693 & .000 \\
\hline Age & .403 & .532 & .056 & .757 & .450 & 1.197 & .613 & .145 & 1.953 & .053 \\
\hline Gender & -2.926 & .741 & -.277 & -3.948 & .000 & -2.961 & .853 & -.242 & -3.470 & .001 \\
\hline Education & 1.400 & .569 & .175 & 2.461 & .015 & 3.033 & .655 & .327 & 4.630 & .000 \\
\hline
\end{tabular}

$\mathrm{R}=0.559 \mathrm{R}$ square $=0.313 \mathrm{~F}(5,146)=13.286 \mathrm{p}=0.00 \| \mathrm{R}=0.565 \mathrm{R}$ square $=0.319 \mathrm{~F}(5,146)=$ $13.685 \mathrm{p}=0.00$.

preoccupation with the internet. Similarly, for predicting dedication $31.9 \%$ of the variance can be explained from internet addiction factors viz, loss of control and interference with daily life and emotional and cognitive preoccupation with internet $\mathrm{F}(5,146)=13.685$ with $\mathrm{p}<0.05$.

In Table 5, the major contributing value $\beta$ is -0.458 which indicates loss of control and interference with daily life is the major factor affecting the vigor of the students. Next, the same factor seems to be impacting the dedication level of the student with $\beta$ value $=-0.408$. Then comes emotional and cognitive preoccupation with the internet which has a relatively less but significant impact on the vigor of the student with $\beta=-0.057$. While the last $-0.007 \beta$ value is the least significant value indicating the less significant relationship between the emotional and cognitive preoccupation with the internet and dedication.

\section{RESULTS}

Table 1 shows that there is a high degree of correlation with 0.01 significance among many variables. So, there was a need to check if there exists any multicollinearity among variables. The results showed that the value of variance inflation factors (VIF) was well below the suggested cutoff of 3 indicating no multicollinearity among the variables. Further, the table shows the means, standard deviations, and correlations among the variables.

H1: ECPI has a negative impact on students' vigor.

As hypothesized, the emotional and cognitive preoccupation with the internet rises in a student it would have a negative effect on the vigor of the student. As the students indulge more and more on the internet e.g. WhatsApp Facebook YouTube, the student's vigor in terms of their studies will get impacted negatively. It will reduce the vigor of the student leading to a decrease in academic engagement. The results in Table 5 show a negative relationship between Emotional and cognitive preoccupation with the internet and vigor meaning when there is a rise in the emotional and cognitive preoccupation with the internet the vigor in studies decreases $(\beta=-0.57, \mathrm{p}<0.05)$. 
H2: LOC has a negative impact on students' vigor.

The second hypothesis proposed was the loss of control and interference with daily life has a negative impact on students' vigor. When the students display excessive involvement in the internet and smartphones and devices, they get so immersed in the activity that they tend to ignore their dayto-day activities like assignments and lectures and disrupts their daily life. When the loss of control increases then the vigor of the students towards their studies is likely to decrease. It includes control variables like age, education, and gender. The results are shown in Table 5 to support our hypothesis and say that there exists a negative relationship between loss of control and interference with daily life and vigor of the students. When there is an increase in the loss of control and interference in daily activities the vigor of the student decreases enormously $(\beta=-0.457, \mathrm{p}<0.05)$.

H3: ECPI has a negative impact on students' dedication.

The third hypothesis proposed is, there exists a negative relationship between the emotional and cognitive preoccupation with the internet and the dedication of the students. The students who are addicted to the internet are more likely to indulge a lot in instant messaging, WhatsApp, Facebook, and YouTube, online gaming, etc. which might make them feel jealous of others and overwhelm them leading to depression and other issues and it may suck out the enthusiasm the students had. Thus, resulted in decreased dedication towards studies. The results in Table 5 show that there exists a low negative relationship between the emotional and cognitive preoccupation with the internet and the dedication of the students. $(\beta=-0.007, \mathrm{p}<0.005)$.

H4: LOC has a negative impact on students' dedication.

Finally, as hypothesized, the loss of control and interference with daily life has a negative relationship with the dedication of the students. The more the student loses his control over the usage of the online activities he tends to get more indulge in the activity leading to reduces attention to studies and class activities. The online chats and videos keep them so engaged that the addiction causes them to neglect their studies and ultimately the student losses his dedication towards studies. The results in Table 5 also shows the negative relationship between loss of control and interference with daily life and dedication of the students $(\beta=-0.408, \mathrm{p}<0.05)$.

Thus, all the above hypothesis is supported by our results displayed in the above tables.

\section{DISCUSSION AND CONCLUSION}

The internet and smartphones have a profound positive effect on students in terms of helping them in their studies, educational courses, and subjects (Woodcock et al., 2012). Although the internet and smartphones have been around for quite a while benefiting its users in many ways and many studies have shown that excessive utilization of the benefits will ultimately lead to negative effects on their academic performance (Froese et al., 2012; Bohlander, 2012) but very few studies have tried to understand how internet addiction disrupts academic learning. This study has tried to understand this gap by involving two aspects of internet addiction - emotional and cognitive preoccupation with the internet and loss of control and interference with daily life and tried to understand its impact on student's academic engagement in terms of their vigor and dedication towards studies.

The study shows that only $6.58 \%$ of the students belong to the severe category of internet addiction. The severe category indicates that internet usage is the highest causing significant problems in life. One should evaluate the possible reasons for problems caused by high internet usage. On the other hand, but $63.16 \%$ of the students are in the moderate category of internet addiction indicating 
the frequent or occasional problems created by the internet which can be transformed into a severe category if proper actions are not taken. According to the author's instructions, the score in the moderate category indicates the prevalence of addiction to the internet. Internet addiction is higher among students spending more time on the internet or internet-enabled devices.

According to the analysis, internet addiction (consisting of both ECPI and LOC) has a negative impact on the academic engagement of the students. However, the impact of the loss of control and interference with daily life has a more profound effect on the vigor of the student as compared to emotional and cognitive preoccupation with the internet. Which is in contrast with the earlier studies (Cernja, 2019) suggesting that the students neglect their day-to-day activities and lose control of their life.

Similarly, when it comes to the dedication of the student towards their studies the results say that the loss of control and interference with daily life has a major negative impact as compared to emotional and cognitive preoccupation with the internet which has very little negative impact on the dedication of students towards their studies. Both the loss of control and interference with daily life and emotional and cognitive preoccupation with the internet are aspects determining internet addiction indicating the negative impact on students' engagement, still, the contribution of LOC remains high as compared to ECPI in impacting the students' engagement negatively.

Hence, there is a need to understand the factors contributing to the loss of control and interference with the daily lives of students so that appropriate action and solution could be suggested to reduce this aspect of addiction. The results say that there is a negative effect of internet addiction on students' academic engagement. The excessive use of the internet disrupts the day-to-day life of students by preoccupying or overly relying on online activities and thus losing control of daily activities like completing assignments, projects, loss of attention during lecture hours This needs to be taken care of by understanding the factors which cause students to over-rely on the internet and thereby channeling their energy in required activities.

\section{LIMITATIONS AND FUTURE RESEARCH}

The data collected is from a single institute at a period. Hence, a cross-sectional study was conducted within a limited scope to understand the internet addiction impact on a smaller scale. However, future research can explore by widening the scope by taking larger samples and may carrying out longitudinal studies. Although, internet addiction is not a new concept it has been for decades with constantly adding new features. It may have many new variables that have not been accounted for in this study. This study has a limited number of variables. There could be many variables that can extend this study. The model considered here is very simple without any moderators or mediators. Further study could explore studying this topic with various mediators or moderators. This study only focuses on business students. Students from diverse areas and levels could be selected to generalize the study. 


\section{REFERENCES}

Andangsari, E. W., Djunaidi, A., Fitriana, E., \& Harding, D. (2019). Indonesia Problematic Internet Use Scale. Journal of Physics: Conference Series, 1175, 012239-012239. doi:10.1088/1742-6596/1175/1/012239

Araby, E. M., El-Raouf, M. S. E. A., \& Eltaher, S. (2020). Does the nature of the study affect internet use and addiction? Comparative- study in Benha University, Egypt. Systematic Reviews in Pharmacy, 11(3), 465-471.

Arefin. (2017). Impact of smartphone addiction on academic performance of business students: a case study. Independent Journal of Management \& Production, 8(3).

Awan, M., \& Khan, H. (2017). Status of Internet Addiction among college students in South Korea. $e$-Journal of Social \& Behavioural Research in Business, 8(1), 91-105.

Beard, K. W. (2005). Internet Addiction: A Review of Current Assessment Techniques and Potential Assessment Questions. Cyberpsychology \& Behavior, 8(1), 7-14. doi:10.1089/cpb.2005.8.7 PMID:15738688

Beard, K. W., \& Wolf, E. M. (2001). Modification in the Proposed Diagnostic Criteria for Internet Addiction. Cyberpsychology \& Behavior, 4(3), 377-383. doi:10.1089/109493101300210286 PMID:11710263

Brady, K. (1995). Dropouts rise a net result of computers. The Buffalo Evening News. American Psychiatric Association.

Černja, I., Vejmelka, L., \& Rajter, M. (2019). Internet addiction test: Croatian preliminary study. BMC Psychiatry, 19(1), 388. doi:10.1186/s12888-019-2366-2 PMID:31805882

Chukwuere, J.E., \& Chuckwuere, P.C. (2017). The Impact of Social Media on Social Lifestyle: A Case Study of University Female Students. Journal of Gender \& Behaviour.

Durak, H. Y. (2019). Investigation of nomophobia and smartphone addiction predictors among ado- lescents in Turkey: Demographic variables and academic performance. The Social Science Journal, 56(4), 492-51. doi:10.1016/j.soscij.2018.09.003

Faraci, P., Craparo, G., Messina, R., \& Severino, S. (2013). Internet Addiction Test (IAT): Which is the Best Factorial Solution? Journal of Medical Internet Research, 15(10), e225. doi:10.2196/jmir.2935 PMID:24184961

Fioravanti, G., \& Casale, S. (2015). Evaluation of the Psychometric Properties of the Italian Internet Addiction Test. Cyberpsychology, Behavior, and Social Networking, 18(2), 120-128. doi:10.1089/cyber.2014.0493 PMID:25684612

Froese, A. D., Carpenter, C. N., Inman, D. A., Schooley, J. R., Barnes, R. B., Brecht, P. W., \& Chacon, J. D. (2012). Effects of classroom cellphone use on expected and actual learning. College Student Journal, $46(2), 323$.

Fu, K.-W., Chan, W. S. C., Wong, P. W. C., \& Yip, P. S. F. (2010). Internet addiction: Prevalence, discriminant validity and correlates among adolescents in Hong Kong. The British Journal of Psychiatry, 196(6), 486-492. doi:10.1192/bjp.bp.109.075002 PMID:20513862

Griffiths, M. (1996). Technological addictions. Clinical Psychology Forum, 161-162.

Jeffery, R., \& Doron, A. (2013). Cell phone nation: How mobile phones have revolutionized business, politics and ordinary life in India. Hachette India.

Joe, W., Kumar, A., \& Rajpal, S. (2018). Swimming against the tide: Economic growth and demographic dividend in India. Asian Population Studies, 14(2), 211-227. doi:10.1080/17441730.2018.1446379

Keelery, S. (2020). Number of internet users in India from 2015 to 2020 with a forecast until 2025. Statista - The Statistics Portal. Retrieved October 16, 2020 https:/www.statista.com/statistics/255146/number-of-internetusers-in-india/

Lee, L.-F., Liu, X., \& Lin, X. (2010). Specification and estimation of social interaction models with network structures. The Econometrics Journal, 13(2), 145-176. doi:10.1111/j.1368-423X.2010.00310.x

Maheshwari, S. K., \& Preksha, S. (2018). Internet Addiction: A Growing Concern In India. Indian Journal of Psychiatric Nursing, 15(1), 61-61. doi:10.4103/2231-1505.262510 
Nalwa, K., \& Anand, A. P. (2003). Internet Addiction in Students: A Cause of Concern. Cyberpsychology \& Behavior, 6(6), 653-656. doi:10.1089/109493103322725441 PMID:14756932

Schaufeli, W. B., \& Bakker, A. B. (2004). Job demands, job resources, and their relationship with burnout and engagement: A multi-sample study. Journal of Organizational Behavior, 25(3), 293-315. doi:10.1002/job.248

Schaufeli, W. B., Bakker, A. B., \& Salanova, M. (2006). The Measurement of Work Engagement with a Short Questionnaire. Educational and psychological measurement. Educational and Psychological Measurement, 66(4), 701-716. doi:10.1177/0013164405282471

Schaufeli, W. B., Salanova, M., González-Romá, V., \& Bakker, A. B. (2002). None. Journal of happiness studies. Journal of Happiness Studies, 3(1), 71-92. doi:10.1023/A:1015630930326

Shambare, R. (2012). Are mobile phones the 21 st century addiction? African Journal of Business Management, $6(2)$.

Shambare, R., Rugimbana, R., \& Zhowa, T. (2012). Are mobile phones the 21st century addiction? African Journal of Business Management, 6(2), 573.

Shamimul, I. (2018). From ICT adoption to ICT addiction: The mediating factors between the use of ICT and learning performance. International Journal of Electronic Commerce Studies, 9(2), 133-159.

Sharma, K.D., Gupta, I.D., Sharma, R., \& Sharma, D. (2016). Internet pattern among high school students of Jaipur city: AS descriptive study. International Multi Speciality Journal of Health, 5(2), 25-31.

Sharma, M., Shyam, H. R., \& Selvan, T. P. (2016). Exploration of Technology Use Pattern Among Teenagers And Its Relationship With Psychological Variables. Academic Press.

Tindell, D. R., \& Bohlander, R. W. (2012). The Use and Abuse of Cell Phones and Text Messaging in the Classroom: A Survey of College Students. College Teaching, 6O(1), 1-9. doi:10.1080/87567555.2011.604802

Vaidya, D. A., Pathak, V., \& Vaidya, A. (2016). Mobile Phone Usage among Youth. International Journal of Applied Research and Studies, 5(3). Advance online publication. doi:10.20908/ijars.v5i3.9483

Wanajak, K. (2011). Internet use and its impact on secondary school students in Chiang Mai, Thailand (Doctoral dissertation). Edith Cowan University.

Woodcock, B., Middleton, A., \& Nortcliffe, A. (2012). Considering the Smartphone Learner: an investigation into student interest in the use of personal technology to enhance their learning. Student Engagement and Experience Journal, 1(1).

Yafi. (2018). The effects of using social network sites on academic performance: the case of Qatar. Journal of Enterprise Information Management, 31(3), 446-462.

Yang, C.-T., Chen, T.-T., \& Tung, H.-Y. (2007). A Dynamic Domain-Based Network Information Model for Computational Grids. Future Generation Communication and Networking.

Yeap, J. (2016). Exploring the impact of internet addiction on academic engagement: A preliminary study on undergraduates. Indian Journal of Management Science, 6, 1-9.

Anjali Singh is a research scholar (Organization Behaviour and Human Resource Management) at the National Institute of Industrial Engineering, Mumbai, India. 